Kory Melnick

Dalhousie University, Halifax, Nova Scotia, Canada

Tamanna Moharana

Dalhousie University, Halifax, Nova Scotia, Canada

Rémi Toupin

Université du Québec à Montréal, Montréal, Québec, Canada

Pallavi Gone

Dalhousie University, Halifax, Nova Scotia, Canada

Bertrum MacDonald

Dalhousie University, Halifax, Nova Scotia, Canada

Philippe Mongeon

Dalhousie University, Halifax, Nova Scotia, Canada

\title{
The intersection of shark research, policy and the public: a bibliometric and altmetric view (Paper)
}

\begin{abstract}
Sharks have traditionally been portrayed as dangerous animals by modern media, contributing to a negative perception in the public eye. On one hand, despite some species being listed as critically endangered, news about the perceived risk of sharks for humans protrudes more than other topics. On the other hand, conservation topics tend to focus on specific topics, such as finning, highlighting the divergence between scientific and mediatic discourses about sharks. Our research compares the attention of shark research topics across citations, tweets, news and policy mention to assess the salience of specific themes. We find that citations are evenly distributed across research communities, tweets and policy mentions exhibit a significant focus on conservation, and news mentions tend to focus on more sensationalist topics such as shark attacks or the repercussions of fisheries on coral reefs.
\end{abstract}

\section{Introduction}

Popular media and news sources have created a trending narrative that sharks are dangerous apex predators that jeopardize human safety and should be feared, perpetuating an association between sharks and risk (Friedrich et al., 2014; Le Busque et al., 2021; O'Bryhim \& Parsons, 2015). Muter et al. (2013) found that about $50 \%$ of news reports focus on shark attacks, while only $11 \%$ mention shark conservation. However, each year, about four people are killed by sharks compared to the 70 million sharks killed each year (Myrick \& Evans, 2014). Shark 
species associated with attacks get a lot of exposure, while other critically endangered species do not get much exposure (Muter et al., 2013; Sabatier \& Huveneers, 2018). This suggests a media focus on prioritizing human safety over species conservation. Shark populations are suffering as a result of this biased media portrayal, which impacts the regulation of marine ecosystems (Myrick \& Evans, 2014). Exposure to sharks substantially affects public perception and people living in coastal areas and aware of sharks in their local waters have a greater knowledge and understanding of sharks and their value to the environment (Friedrich et al., 2014). However, most individuals will never encounter sharks in the wild and the media plays a significant role in shaping and manipulating, public perception.

Information about sharks publicized through popular or social media platforms can feature factual or fictional information. Therefore, it may contribute to a public perception that is exaggerated or untrue. As a result, the perpetuation of negative stereotypes about sharks will continue to mislead the public through narratives rooted in public fear rather than popularizing scientific truth that works to protect sharks and rebrand their image in the public eye (Panoch \& Pearson, 2017) Even when the media does pay attention to conservation issues, the focus tends to be on more sensationalist or glamorous topics, leading the public to perceive, for instance, shark finning as the only major threat that sharks face (Shiffman et al., 2020). Yet scientists agree that most significant threats are related to other issues such as overfishing, bycatch, and shark meat trade that do not get the appropriate amount of media coverage (Myrick \& Evans, 2014; Shiffman et al., 2020). This lack of public awareness about sharks is reflected in the implementation of potentially inadequate conservation initiatives and policies (Crossley et al., 2014; McCagh et al., 2015; O’Bryhim \& Parsons, 2015). According to Shiffman et al. (2020), this inability of science to properly guide and shape public opinion lies in the biased reporting of scientific research in the news. This work-in-progress combines bibliometrics and altmetrics to address this particular issue by looking at the distribution of scientific and media attention across the areas of shark-related research. This will provide an empirical basis to examine the discrepancies between the scientific and popular discourses about sharks and their implications for conservation and environmental management. Questions orienting our research are as follow:

1. What different research communities can we identify from the shark-related literature?

2. How is scientific attention (citations) distributed across these communities?

3. How is media attention (e.g., tweets, news mention) distributed across these communities?

\section{Methods}

We provide answers to these questions by applying standard bibliometrics, altmetrics, network analysis, and textual analysis methods to all Web of Science publications containing the term "shark" and published between 1980 and 2020. We use the citation links (bibliographic coupling merge with co-citations) between these publications to generate the publication network, which provides an overview of the shark research landscape. We accomplished our analysis by using 
the igraph package in $\mathrm{R}$. We used a Louvain community detection algorithm to identify the distinct research communities (i.e. publication clusters) and describe them by extracting the specific terms used in the title, abstract and keywords of the publications. We subsequently identified the largest (macro-clusters), intermediary (meso) and smaller (micro) clusters of research, refining the topical structures through each step.

We assessed the topics of research at all clustering levels (macro, meso, micro) by examining the words in the abstracts with the highest tf-idf, thus highlighting the specific terms characterizing a community in comparison to the others. We considered each community as a document for our analysis. Using base and tidytext functions in $\mathrm{R}$, we cleaned the abstracts by removing punctuations, editing symbols, numbers, and bringing all characters to lower cases. We also removed all papers that did not include an abstract. We then removed stopwords and general terms to our dataset (such as shark and species). Using the tidytext package, we then generated tokens for each word, counting their frequency within documents. We subsequently computed the tf-idf associated with each term and used the top ten words by clusters to assess the topics discussed in each community. We looked at the citation counts and media attention (tweets, news, policy mentions) of each community to examine which topics generated interest.

\section{Results}

We obtained 18 clearly delineated macro clusters of research which further divide into 94 mesoclusters and 263 micro-clusters as we increase the granularity of our analysis. The largest communities of research, highlighted in table 1 , focus on topics related to biology (community 4) paleontology (community 5), conservation (community 6) and ecology (community 18). The topics of meso-clusters and micro-clusters echo the larger of larger clusters across all of our papers. Focusing on the topic of conservation, the four meso-clusters of research of community 6 deal with topics such as coral reef management, bycatch, fisheries management, and trade. These topics gain specificity in micro-clusters of research, for example by highlighting geographical considerations (vancouver, chilean, mediterranean, indoaustralasian). Several clusters were not directly related to shark research and were removed for subsequent analyses: macro-clusters 2 (tapeworms, which sharks frequently host), 7 (business sharks), 8 (SharkSQL programming language), 11 (lawyers as sharks), 12 (stromatolites and Hamelin means Shark Bay), 15 (underwater acoustics likely referencing the Yellow Shark 94 underwater experiment), and 16 (sharkskin instability in industrial extrusion).

Table 1. Topical macro-clusters of shark research assessed through the 10 words with the highest tf-idf. 
Communities of shark research (co-citations and bibliographic coupling)

\begin{tabular}{|c|c|c|}
\hline Macro-community & $\mathrm{N}$ papers in community & Top 10 words used in papers abstracts \\
\hline 1 & 644 & rectal, cotransporter, nkcc, nakatpase, nakcl, cnp, basolateral, cotransport, adenosine, natriuretic \\
\hline 2 & 268 & scolex, cestode, microtriches, bothridial, bothridia, paraorygmatobothrium, calliobothrium, acanthobothrium, tetraphyllidean, phoreiobothrium \\
\hline 3 & 358 & whale, typus, manta, individuals, tourism, rhincodon, zooplankton, sightings, alfredi, photoidentification \\
\hline 4 & 1725 & females, growth, $\mathrm{cm}$, males, population, reproductive, tl, maturity, bertalanffy, linfinity \\
\hline 5 & 1684 & teeth, tooth, fossil, drag, nov, cretaceous, enameloid, miocene, jurassic, triassic \\
\hline 6 & 1585 & fishing, fisheries, marine, catch, conservation, bycatch, fishery, longline, catches, cpue \\
\hline 7 & 52 & firms, patent, antitakeover, corporate, takeover, managerial, boards, poison, atps, shareholder \\
\hline 8 & 10 & query, hive, spark, sql, analytics, impala, hiveql, oceanrt, bdas, hadoop, inmemory \\
\hline 9 & 572 & bay, dolphins, seagrass, bottlenose, dugongs, everglades, dugong, soil, calves, alliances \\
\hline 10 & 1063 & genes, receptor, antibodies, mhc, hox, tcr, vnar, ignar, squalamine, cdr \\
\hline 11 & 8 & patients, metaphors, metaphor, literal, schizophrenia, metaphorical, abstraction, lawyer, aptness, figurative, literally \\
\hline 12 & 197 & microbial, stromatolites, mats, microbialites, carbonate, mat, microbialite, stromatolite, hamelin, thrombolites \\
\hline 13 & 946 & fish, prey, diet, trophic, delta, hg, mercury, iri, mehg, thg \\
\hline 14 & 445 & sulfate, squalene, cs, collagen, chondroitin, gelatin, galnac, slo, glca, dermatan \\
\hline 15 & 11 & acoustic, inversion, waveguide, broadband, geoacoustic, wavenumbers, spacefrequency, wavenumber, mbmf, mrea \\
\hline 16 & 21 & melt, sharkskin, die, fracture, slip, extrusion, instabilities, extrudate, extruded, mpe \\
\hline 17 & 500 & olfactory, sensory, visual, neurons, electrosensory, telencephalon, retina, ampullary, pallium, raphe \\
\hline 18 & 1279 & movement, patterns, habitat, movements, acoustic, juvenile, tagged, nursery, telemetry, levy \\
\hline
\end{tabular}

In terms of academic attention, documented in table 2, the larger communities 4, 5, 6, and 18 do not stand out as being more heavily cited, with an average of 19 to 31 citations per community, although papers of communities 6 and 18 tend to be slightly more cited as indicated by an above average $\mathrm{z}$-score. Community 6 , dealing with conservation and fisheries, stands out for media attention, however, being the most tweeted and mentioned in policy documents, and second in terms of news attention. Communities 3 and 18, respectively dealing with tourism issues and ecology, also have a high share of media attention in comparison to other communities. Indicators of attention in meso and micro-clusters highlight a discrepancy not only between citations and media attention but also between tweets, news and policy mentions. Tweets are higher in clusters dealing with tourism and the effects of fisheries on the ecosystem, whereas news mentions are higher for sensational events and shark predation (meso community 92). Finally, policy mentions are higher in topics dealing with environmental management issues, such as the effects of fisheries on ecosystems.

Table 2. Scientific and media attention to shark research assessed through z-scores of citations, tweets, news, and policy mentions 


\begin{tabular}{|c|c|c|c|c|c|c|}
\hline \multicolumn{7}{|c|}{ Communities of shark research (co-citations and bibliographic coupling) } \\
\hline $\begin{array}{l}\text { Macro- } \\
\text { community }\end{array}$ & $\begin{array}{l}\text { N papers in } \\
\text { community }\end{array}$ & $\begin{array}{l}\text { Z-score } \\
\text { citations }\end{array}$ & $\begin{array}{l}\text { Z-score } \\
\text { tweets }\end{array}$ & $\begin{array}{l}\text { Z-score news } \\
\text { mentions }\end{array}$ & $\begin{array}{c}\text { Z-score policy } \\
\text { mentions }\end{array}$ & $\begin{array}{l}\text { Z-score all media } \\
\text { mentions }\end{array}$ \\
\hline 1 & 644 & 0.96 & -1.19 & -1.43 & -0.78 & -1.24 \\
\hline 3 & 358 & -0.22 & 1.42 & 1.49 & 0.31 & 1.58 \\
\hline 4 & 1725 & -0.21 & -0.38 & -0.39 & 1.13 & -0.38 \\
\hline 5 & 1684 & -0.67 & -0.10 & 0.91 & -0.85 & 0.01 \\
\hline 6 & 1585 & 0.16 & 1.97 & 1.07 & 2.56 & 1.86 \\
\hline 9 & 572 & 0.74 & -0.17 & 0.07 & -0.10 & -0.19 \\
\hline 10 & 1063 & 0.99 & -0.66 & -0.43 & -0.78 & -0.58 \\
\hline 13 & 946 & 0.33 & 0.10 & -0.10 & 0.18 & 0.05 \\
\hline 14 & 445 & 0.52 & -1.05 & -1.43 & -0.71 & -1.04 \\
\hline 17 & 500 & -0.64 & -0.44 & 0.69 & -0.51 & -0.36 \\
\hline 18 & 1279 & 0.64 & 1.15 & 0.72 & 0.11 & 1.08 \\
\hline
\end{tabular}

\section{Discussion and conclusion}

Our results highlight the discrepancies between scientific and media attention to shark research. While citations are evenly distributed across communities of research, tweets, news and policy mentions tend to focus on specific topics. Tweets show an attention to conservation issues, probably as a result of an uptake by several groups ranging from researchers to policy actors and environmental organizations. Further research to understand the contexts of Twitter sharing of shark research may highlight the precise circumstances that make it suitable to discuss shark conservation topics. News mentions for their part focus more on sensationalist topics such as shark predation and risks to humans. Finally, policy mentions tend to focus more on topics relevant to environmental management. While our results are preliminary, we provide an empirical basis about how information about shark research moves across different communities and media. As different media focus on distinct topics, understanding these discrepancies will contribute to marine conservation efforts as we further document how information may contribute to specific discourses of initiatives.

\section{References}

Crossley, R., Collins, C. M., Sutton, S. G., \& Huveneers, C. (2014). Public Perception and Understanding of Shark Attack Mitigation Measures in Australia. Human Dimensions of Wildlife, 19(2), 154-165. https://doi.org/10.1080/10871209.2014.844289

Friedrich, L. A., Jefferson, R., \& Glegg, G. (2014). Public perceptions of sharks: Gathering support for shark conservation. Marine Policy, 47, 1-7. https://doi.org/10.1016/j.marpol.2014.02.003 
Le Busque, B., Dorrian, J., \& Litchfield, C. (2021). The impact of news media portrayals of sharks on public perception of risk and support for shark conservation. Marine Policy, 124, 104341. https://doi.org/10.1016/j.marpol.2020.104341

McCagh, C., Sneddon, J., \& Blache, D. (2015). Killing sharks: The media's role in public and political response to fatal human-shark interactions. Marine Policy, 62, 271-278. https://doi.org/10.1016/j.marpol.2015.09.016

Muter, B. A., Gore, M. L., Gledhill, K. S., Lamont, C., \& Huveneers, C. (2013). Australian and U.S. News Media Portrayal of Sharks and Their Conservation: Media Portrayal of Sharks. Conservation Biology, 27(1), 187-196. https://doi.org/10.1111/j.15231739.2012.01952.x

Myrick, J. G., \& Evans, S. D. (2014). Do PSAs Take a Bite Out of Shark Week? The Effects of Juxtaposing Environmental Messages With Violent Images of Shark Attacks. Science Communication, 36(5), 544-569. https://doi.org/10.1177/1075547014547159

O’Bryhim, J. R., \& Parsons, E. C. M. (2015). Increased knowledge about sharks increases public concern about their conservation. Marine Policy, 56, 43-47. https://doi.org/10.1016/j.marpol.2015.02.007

Panoch, R., \& Pearson, E. L. (2017). Humans and Sharks: Changing Public Perceptions and Overcoming Fear to Facilitate Shark Conservation. Society \& Animals, 25(1), 57-76. https://doi.org/10.1163/15685306-12341441

Sabatier, E., \& Huveneers, C. (2018). Changes in Media Portrayal of Human-wildlife Conflict During Successive Fatal Shark Bites. Conservation and Society, 16(3), 338. https://doi.org/10.4103/cs.cs_18_5

Shiffman, D. S., Bittick, S. J., Cashion, M. S., Colla, S. R., Coristine, L. E., Derrick, D. H., Gow, E. A., Macdonald, C. C., More O'Ferrall, M., Orobko, M., Pollom, R. A., Provencher, J., \& Dulvy, N. K. (2020). Inaccurate and Biased Global Media Coverage Underlies Public Misunderstanding of Shark Conservation Threats and Solutions. IScience, 23(6), 101205. https://doi.org/10.1016/j.isci.2020.101205 